\title{
À procura do berço esplêndido: a trajetória de uma geração em $O$ filho eterno
}

William Moreno Boenavides ${ }^{1}$

O assunto central da obra O filho eterno (2007), de Cristóvão Tezza, é a relação do pai com o filho Felipe, portador da síndrome de Down. O que se pretende no presente trabalho, no entanto, é analisar a trajetória social do pai, associando sua relação com o filho às situações políticas trazidas à tona pela obra, com ênfase no que diz respeito aos períodos da ditadura militar e da chamada redemocratização do Brasil.

No aspecto temporal, o romance apresenta uma divisão da seguinte ordem: um tempo que pode ser referido como o presente da narrativa, que inicia com o nascimento de Felipe; e outro que corresponde ao passado do pai de Felipe, trazido à tona por meio de flashbacks. Como comentário complementar, é necessário lembrar que, no caso do presente da narrativa, entre os protagonistas, apenas Felipe é nomeado; já no passado do pai, os personagens em geral são nomeados.

Nesse trabalho, organizarei a narrativa de forma cronológica para estabelecer comparações da relação do protagonista com o tempo histórico no qual ele está inserido. Ficará de fora apenas uma passageira referência à infância passada em Santa Catarina, por não trazer referências suficientes à análise que aqui se pretende.

Nesse sentido, nossa cronologia inicia durante a juventude do protagonista, transcorrida no período da ditadura militar no Brasil, e na qual ele refere o uso de drogas e a presença de pequenos atos de rebeldia. Esse momento é retomado quando ele telefona aos parentes para anunciar o nascimento do filho, e lembra-se de sua adolescência, na qual, aos 15 anos (em 1967, portanto, já que tanto o pai quanto a mãe nasceram em 1952), cheirava alucinógenos nas praças de Curitiba. Sem pai, mas com mãe, casa, boa escola e um desejo de virar o mundo do avesso, decide parar depois de ter passado dois dias com um zumbido nos ouvidos devido ao uso das drogas.

Recordação do mesmo período reaparece no momento em que, já tendo desistido de que o laudo médico estivesse errado e que o filho não fosse

${ }^{1}$ Doutorando em literatura brasileira e professor do Instituto Federal Sul-Riograndense (IFSul), Sapucaia do Sul, RS, Brasil. (Dorcid.org/0000-0002-0507-2105. E-mail: boenavides@ gmail.com 
portador da síndrome de Down, começa a buscar soluções para que os efeitos da síndrome pareçam menores, para inserir o filho no mundo da "normalidade". Como é dito no livro, é quando começa a corrida de cavalo pelas regras dos outros. O pai vê, num recorte de jornal, uma clínica do Rio de Janeiro que oferece um programa completo de estimulação precoce para crianças com síndrome de Down. Aí, entre o conhecimento do anúncio e a ida à clínica, o pai de Felipe lembra, novamente, caminhando pelas ruas de Curitiba, alguns atos de vandalismo e uso de alucinógenos que protagonizou quando tinha 15 anos. Enquanto caminha, seus pensamentos o levam a perceber que não há retorno para o que vive agora, sente o peso da situação, a garganta aperta e ele chora. Muda o caminho, mas todas as ruas não levam a lugar nenhum.

A referência a outro momento da juventude, de alistamento e dispensa da marinha, acontece quando passa a se delinear um processo de espelhamento entre pai e filho. Ao comentar que Felipe começou a dar os primeiros passos com 2 anos e dois meses, o pai se lembra de que também nunca foi muito precoce. As experiências do filho passam a servir de reflexão para o pai em relação a suas próprias experiências. Nesse sentido, a recusa do filho, quando este já tinha 5 ou 6 anos, em ir buscar três pés de alface no vizinho (o que rendeu umas lapadas com uma peça de compensado na bunda de Felipe) lembra-lhe sua passagem pelo serviço militar da marinha (quando aproveitava os intervalos das aulas e dos treinamentos para ler). $\mathrm{O}$ gesto do pai equivaleu a dizer "não", a recusar a universidade e a vida no "sistema". Coisa de que se arrependeu, pois pediu sua dispensa na primeira oportunidade.

Estamos em 1981, Felipe tem três meses e, pouco antes de o pai e a mãe irem procurar a clínica no Rio de Janeiro, vão visitar um antigo amigo do pai de Felipe, dos tempos em que atuava em um grupo de teatro. $\mathrm{O}$ amigo mora na Urca e os recebe com o namorado. Com ele, o pai recorda algumas apresentações e viagens pelo Brasil.

Quando chegam à clínica do anúncio do jornal, a preleção é feita pelo diretor da clínica, um homem imenso alojado numa cadeira. O tetraplégico é, assim, um exemplo da conquista do método que apregoa. Não deixa de falar nas críticas que recebem e assume que não há problemas em criarem "macaquinhos com reflexos condicionados", porque, "sim, todos queremos crianças bem-educadas, com padrões de comportamento que não agridam os olhos ou a alma" (Tezza, 2010, p. 88). O pai, depois de ter recebido as folhas mimeografadas com as instruções 
dos exercícios que deverá fazer com seu filho nos próximos anos, relembra alguns episódios de seu tempo de estudante em Coimbra, incluindo o envolvimento com o Partido Comunista. O slogan da clínica "os pais são a solução, não o problema" ressoa em sua cabeça, e o casal ouve uma explicação sobre as etapas da evolução neurológica.

Demais referências sobre esse período são dadas na sequência, quando os pais simulam os movimentos de uma caminhada. Essa parte do livro, além da descrição do cotidiano do tratamento de Felipe, dá ao leitor informações sobre o trabalho de escrita do pai (que divide seu dia entre as sessões de estímulo e a escrita do livro em que trabalha, o Ensaio da paixão) e de outro momento de seu passado, quando esteve como imigrante ilegal, na Alemanha (fez também uma passagem por Paris), em 1975, durante a paralisação das aulas em Coimbra, onde iria começara a estudar, em virtude da Revolução dos Cravos.

Sem saber uma palavra em alemão, trabalhou em um hospital, na lavanderia, na limpeza e na cozinha (de onde, aproveitando o que considerava desperdício dos alemães, retirava algumas coisas para comer...). Suas recordações mostram que seus movimentos repetitivos para execução de suas tarefas (movimentos que, em suas constantes referências ficcionais, o fazem comparar-se a Chaplin na linha de produção) lembram os exercícios do filho. No hospital, procurou um argelino, um certo Herr Pinheiro, que sabia todas as línguas do mundo, e recebeu instruções sobre seu trabalho. Dividiria a limpeza de um andar com um turco. Eles deveriam limpar os quartos e os corredores. O turco o deixou com o pior trabalho, limpar os quartos cheios de obstáculos e de enfermos, enquanto o outro cuidaria apenas do corredor.

Quando um brasileiro veio trabalhar ali, ele pensou em fazer o mesmo, mas não tinha o dom nietzschiano da vontade de poder. $\mathrm{O}$ rapaz quis roubar uma calculadora de uma das salas, mas, ao ser ameaçado por ele de ser denunciado, desistiu, dizendo tratar-se de uma brincadeira. Relembra ainda um sábado livre em que, passando por Frankfurt, entra numa livraria. Inúmeros clássicos (Cortázar, Dickens, Thomas Mann, Scott Fitzgerald, Sartre etc.) inacessíveis para ele, que não lê em alemão. Procura livros de autores brasileiros e encontra apenas três títulos de Jorge Amado. "Os escritores brasileiros somos pequenos ladrões de sardinha, Brás Cubas inúteis, ele quase se vê dizendo em voz alta, na última prateleira, folheando uma bela e incompreensível edição de Dom Quixote" (Tezza, 2010, p. 104). Seu 
trabalho no hospital alemão, recorda-se ainda, foi interrompido pela revolta dos imigrantes legais, que levou a fiscalização até lá e não deixou outra alternativa a Herr Pinheiro senão demiti-lo.

Em outro momento, a limitação do filho em não conseguir abrir uma porta é contraposta à sua própria (numa rememoração dos trabalhos avulsos que fez, agenciado por um venezuelano, na Alemanha depois que teve que deixar o hospital) experiência de ter pulado uma janela por não aventar a alternativa de que deveria tentar abrir a porta para fora em vez de forçá-la para dentro.

O nascimento do filho, episódio central para a narrativa, se dá no início da década de 1980. A partir disso, o pai sente-se dividido por diversas forças de transformação, de permanência e de desajuste social. No dia desse nascimento, começa o livro, e o pai reflete que, na manhã seguinte, ele seria tão novo quanto o filho. Gosta da imagem que lhe vem à cabeça agora, a de que ele também estaria nascendo, afinal ele também não tem nada ainda, "diria numa espécie de metafísica da competição. Nem casa, nem emprego, nem paz" (Tezza, 2010, p. 10).

As reflexões dele que surgem nesse momento se prendem a suas não realizações e às possíveis alterações pelas quais sua vida passará depois do nascimento, rotina que tenta antecipar para que as coisas não mudem muito. Sabia-se um predestinado à literatura, porém sabia que não havia escrito nada de realmente bom. Esse filhote retardatário dos anos 1970 trabalha revisando dissertações e teses sobre qualquer tema e dá aulas particulares de redação. Desistiu (ou foi desistido pela profissão) de ser relojoeiro, tentativa que empreendeu pelo fascínio infantil dos mecanismos e a delicadeza inútil do trabalho manual.

O trabalho é um elemento que já havia aparecido em suas reflexões um pouco antes, quando precisou preencher o formulário na maternidade. Nessa situação, ele reflete que não consegue viver de seu trabalho verdadeiro - era escritor, como ficamos sabendo nesse momento.

Depois de uma noite difícil, em que dormiu - ou quase dormiu - num sofá vermelho ao lado da cama alta do hospital, vê os bebês no berçário (o que o faz lembrar, do Admirável mundo novo). Agora e para sempre, aquelas crianças estão condenadas ao Brasil e à língua portuguesa.

Vê seu filho e pensa que aquela presença era um nascimento às avessas, agora que ele está do outro lado do balcão, não está mais em berço esplêndido. Perdeu um privilégio: a liberdade, palavra que quer dizer muito. "Poder escrever e dizer tudo ou não poder escrever nem 
dizer nada. Estar dentro da cadeia, estar fora da cadeia" (Tezza, 2010, p. 20). O Brasil está nos últimos minutos de uma ditadura militar, lembrase (estamos no dia 3 de novembro de 1980). Acorda como se fosse um renascimento, garrafinha de uísque vazia.

No quarto, sua mulher pergunta-lhe se havia telefonado aos familiares. Vai fazer isso agora. Ao sair, vê um bonequinho azul pendurado na porta e tenta reconhecer seu filho no berçário, a gaiola pública dos recém-nascidos. O menino receberá o nome de Felipe (o casal preferiu não saber o sexo da criança com antecedência; se fosse menina, seu nome seria Alice). No guichê da recepção, resiste à vontade de pedir para ligar do telefone do hospital e compra fichas para telefonar.

O pai volta ao quarto, a mãe dorme tranquila. Ele se deita no sofá vermelho, que, sendo curto para suas pernas, lembra de súbito um instante perdido na infância. Vê ainda o lustre no alto, com uma das lâmpadas ausentes, fecha os olhos e dorme.

Quando chegam os parentes, recebe os conselhos que todos têm a dar nessa hora, e o pai alardeia (fazendo piada) que havia feito um curso de pai. De fato, era verdade. Do curso, o único conselho que guardou foi o de que os pais deveriam "manter uma boa relação com as sogras, porque os pais precisam eventualmente descansar da criança" (Tezza, 2010, p. 28). Em meio às perguntas sobre a criança e a animação dos parentes, sente-se cansado e com uma ponta da mesma ansiedade de sempre. Quer ir para casa, voltar a sua rotina e se dedicar a seu trabalho atual de escrita: o Ensaio da paixão. Lembra-se, como em outros momentos, de seu velho guru, alguém com quem se aconselhava no passado - precisaria de sua bênção agora.

No entanto, os médicos estão "surpreendentemente sérios, absurdamente sérios, pesados, para um momento tão feliz - parecem militares" (Tezza, 2010, p. 29). A pior notícia vem daqueles que parecem militares. O choque da notícia, na manhã mais brutal da sua vida, foi intenso. $\mathrm{O}$ pai lutou para permanecer no segundo antes da revelação. Não havia como, isso é para sempre. Sentiu a "maior vertigem de sua existência, a rigor a única que ele não teve tempo de domesticar numa representação literária" (Tezza, 2010, p. 30). Nos anos 1980, a doença era conhecida popularmente como "mongolismo". O pai fica aterrado, sabia que a infância teimosamente retardada terminava aqui.

Na sua cabeça, a consciência das limitações eternas do filho. Sabe que portadores da síndrome de Down 
jamais chegarão à metade do quociente de inteligência de alguém normal; que não terão praticamente autonomia nenhuma; que serão incapazes de abstração, esse milagre que nos define; e cuja noção do tempo não irá muito além de um ontem imemorial, milenar e um amanhã nebuloso. Para eles, o tempo não existe. A fala será para sempre um balbuciar de palavras avulsas, sentenças curtas, truncadas; será incapaz de enunciar uma estrutura na voz passiva (a janela foi quebrada por João está além de sua compreensão). $\mathrm{O}$ equilíbrio do andar será sempre incerto, e lento; se os pais se distraem, eles engordarão como tonéis, debaixo de uma fome não censurada pela sensação de saciedade, que neurologicamente demora a chegar. Tudo neles demora a chegar. Não veem à distância - o mundo é exasperadamente curto; só existe o que está ao alcance da mão (Tezza, 2010, p. 34).

Imagina a renovação que sentiria depois do filho morto: a vida recomeça, não é? A isso se mescla o retorno das reflexões que faz sobre suas não realizações. Considera-se sem competência para sobreviver. E essa morte anunciada, parece-lhe, nesse momento, o único lado bom de sua vida.

Ele, que nunca foi exatamente um homem normal, passa a querer a normalidade, da qual Felipe se afasta. $O$ filho pesa como mais uma de suas frustrações: ele que acabou se integrando ao sistema, mas sem nenhuma de suas vantagens, sendo desempregado indócil, escritor sem obra, agora é ainda pai sem filho. Num marcante episódio em casa, a mãe, muito nervosa, diz, no desespero do choro alto: "Eu acabei com a tua vida." Ele silencia, como quem concorda, e se vale disso como novo consolo para si.

Sua preocupação não é com a criança, mas com o espaço que ela ocupa agora em sua vida. Passa a pensar na vergonha, uma das mais poderosas máquinas de enquadramento social que existem, uma chave poderosa da vida cotidiana. Em meio a esses pensamentos, o pai passa a perceber que há algo de errado, não com o filho, mas com ele. Contudo, enquanto a criança e a mãe dormem, ele recorda-se do que a mulher lhe disse - ela acabou com a vida dele - e sente-se mais tranquilo.

Em função da forte probabilidade de portadores da síndrome de Down terem problemas cardíacos, eles procuram fazer exames em Felipe. A divergência entre os diagnósticos de uma jovem médica residente e o de outro médico, um velho senhor cansado, leva-os a procurar outro especialista. O velho, após anunciar que o menino com um bom estímulo, poderá chegar a $50 \%$ ou $60 \%$ da inteligência de uma 
criança normal, ausculta o coração de Felipe e diagnostica a presença de um sopro. A médica examina o menino e contraria o diagnóstico anterior. Há uma pequena disputa na qual o que parecia estar em questão era mais a reputação do experiente médico do que a saúde da criança. A consulta a outro especialista valida o diagnóstico da médica residente, não há nada de errado com o coração de Felipe.

Ainda nesse momento, o que o pai quer é qualquer coisa que não fosse encarar o fato em si. Nessa busca, a vontade de descobrir que seu filho não é doente é tão válida para ele quanto a expectativa da morte da criança. Esse "desejo estúpido de morte não o deixa - há um esforço de derrotá-lo (primeiro a miragem de um engano genético [...], depois a vergonha do próprio sentimento, a estupidez de sua frieza oculta - ele não consegue ocultá-lo" (Tezza, 2010, p. 58).

Revela que não tratará, ao longo de 20 anos, da síndrome de Down em sua escrita. Para ele, nesse momento, ainda, escrever é fingir que não está acontecendo nada.

Essa fase marca o início da ideia de filho que o pai passa a ter em relação a Felipe. E começa aqui, também, a montar a armadilha de que será duro se livrar. O problema não é o filho; o problema é ele.

Ele cuida da casa, dá aulas particulares e revisa teses e dissertações. Indiferente ao fato de o outro romance (Ensaio da paixão, o primeiro acerto de contas com a própria vida, antes do filho) não ter sido publicado, trabalha em outro, Trapo. Acumulam-se as cartas de recusa das editoras. Agora formado em Letras, o pai pensa no que fazer da vida. Recusou tempos atrás o trabalho na redação de um jornal picareta. A mulher está grávida novamente e sentem medo de ter outro filho com Down. Um exame feito em Campinas, no entanto, revela que a criança é geneticamente normal. É uma menina. Esse momento marca mudanças importantes não só no menino, mas também no pai. Ele tenta lutar contra a dificuldade que o filho tem em desenvolver a fala e, nas fotografias que tira, busca ângulos em que o filho não ficará com o rosto que tem, de trissômico. Atordoa-lhe o olhar de Felipe, olhar típico dos portadores da síndrome de Down. Jamais esqueceu o comentário que ouviu, de que seu filho tem o olhar vazio.

Ele muda sua forma de encarar a realidade, é preciso não mentir. Não, o seu filho jamais será uma criança normal - nem chegará perto disso. Viveu uma febre durante dois anos, um breve delírio dos sentidos, um véu de ilusão. 
Um episódio é marcante nessa aproximação entre pai e filho. Felipe tenta subir no banco do carro (o fusca amarelo que os acompanha há tempos). Entre a análise do menino sobre qual a melhor forma de fazer isso e sua manifestação frenética, buzinando ininterruptamente, após ter conseguido subir, o pai faz diversas rememorações. Pensa na teimosia do filho (e na sua própria), na dissolução do grupo de teatro do qual participava (e no qual se sentia paternalmente protegido pelo guru), que foi, para ele, o primeiro momento em que o sonho, de fato, acabou. Recorda a homenagem ao poeta espanhol García Lorca no nome que deu a sua relojoaria, Cinco en Punto - Conserto de relógios. O filho sobe no banco, e ele pensa nos livros não publicados. Tem 30 anos, precisa de dinheiro, pensa na possibilidade de tornar-se professor (logo ele, que sempre sentou próximo à porta para poder ir embora o quanto antes das aulas). A prestação do sobradinho deu um salto de quase $200 \%$. Reclama no banco, diz que não iria pagar essa prestação. As cartas do banco acumulam-se. Não muito adiante, iria perder a casa. Mudam-se e deixam a casa com um amigo que vendia pôsteres na rua, com mulher e filha, para ficarem, enquanto não os tirassem dali. Culpa dos juros exorbitantes que assolavam o país, as pessoas entravam em massa na justiça, ganhando a causa décadas depois. Ele não entra na justiça, detesta a burocracia. O pai agora trabalha em Florianópolis como professor e, mesmo tendo instruído os amigos que ficaram na casa a dizerem que não sabiam onde ele e sua família estavam, o banco acaba localizando sua mulher (no nome de quem estava a casa e que ficara em Curitiba com as crianças). No final, apenas devolvem a casa e está liquidada a dívida.

O filho enfim alcança a direção do carro, torce para um lado, para o outro, imitando o pai, até que descobre a buzina. O barulho incomoda o pai e, numa disputa, o pai está do outro lado da mesma roda em que se agarram. Ambos teimosos, pai e filho são parecidos, espelham-se naquele instante violento e absurdo. $\mathrm{O}$ filho teima, crava os pés no banco, volta a buzinar. O pai explode, dá quatro palmadas em Felipe, "como se a mão do próprio pai estivesse ali de novo reatando o fio da violência que precisaria se cumprir por alguma ordem divina, por alguma ordem do pai" (Tezza, 2010, p. 137). Mas o filho não chora.

No próximo período, será mostrada a ascensão, a estabilidade atingida por ele, que chegará a viver num belo apartamento e a ingressar no circuito oficial da literatura, através das grandes editoras. Pela primeira vez, aos 34 anos, ele tem um emprego fixo, de carteira assinada. Só vê a 
família, no entanto, aos finais de semana, quando volta para Curitiba. Seu trabalho em Florianópolis foi conseguido mediante concurso. Trabalhou lá por dois anos, retornando a Curitiba depois. Mal começa a dar aulas e uma greve interminável se arrasta por cem dias do último governo militar. Ele escreve mais um romance recusado por editoras, Aventuras provisórias. É um período de transição na vida do protagonista - já não é mais o desempregado de antes - e também um período de transição na história do país, o governo militar está chegando ao fim. Essa transição anuncia as mudanças mais efetivas que se dariam no futuro próximo, tanto para o pai de Felipe quanto para o Brasil.

Mais adiante saberemos que o pai, de volta a Curitiba, havia ingressado na vida acadêmica e dá aulas na universidade. Tudo parece bem. Finalmente seu romance Trapo foi publicado por uma grande editora de São Paulo e teve boa recepção. Seu filho e sua filha frequentam a mesma creche. Em meio a reflexões sobre a situação da universidade pública, sobre o Brasil (um país agora vivendo as conquistas da Constituinte de 1988) e sobre as provas de natação de Felipe, sabemos que a ilusão de normalidade que a creche lhe dá dura alguns poucos anos.

A família mora agora num apartamento, e o pai só sentiu a dependência que sentia pelo filho no dia em que Felipe desapareceu pela primeira vez (ele desapareceria em uma ocasião posterior, na praia). O menino estava assistindo televisão e sumiu. O pai procura, vê a porta aberta, Felipe sabia descer os 19 andares pelo elevador. O porteiro não viu. Ele se sente desamparado como quando o menino nasceu, mas agora a culpa é inevitavelmente sua. Procura em locais conhecidos, ninguém viu o menino.

Reflete sobre a condição do filho, como poderia comunicar a alguém quem era? Não havia como. Pensa na nova escola de Felipe, ele reagiu mal nos primeiros meses, isolou-se e ficou silencioso. Em compensação, o menino que já desenhava bem, graças a uma ótima professora, passou a desenhar mais e de modo mais disciplinado. Ao voltar para casa sem o filho, depara-se com a inversão da situação inicial de quando teve a notícia de que seu filho era Down: "o mesmo filho que ele desejou morto assim que nasceu, agora, pela ausência, parece matá-lo" (Tezza, 2010, p. 169).

Precisam procurar a polícia, não tinha outro jeito. Incomoda-se com a ideia de ter que ir a uma delegacia. Recorda-se quando, em 1972, por uma série de equívocos, ele e os demais integrantes de seu grupo teatral foram 
levados para a delegacia sob a acusação de terem invadido uma casa. Estão desesperados, mas um telefonema milagroso de uma vizinha dá um desfecho ao caso. Dois soldados da Polícia Militar encontraram Felipe no pátio da universidade, próximo dali, brincando sobre um jipe sem capota, conversando sozinho, animado ao volante, vivendo seu teatro autista. Quando os pais foram buscar Felipe, os policiais sentiram uma leve desconfiança, pois o menino chamou seu pai pelo nome, não de pai. A mãe, no entanto, foi chamada de Mãezuca. O pai paga os policiais pelo serviço, uma nota de 500 do dinheiro da época, que os policiais titubearam, mas acabaram aceitando. Voltando para casa, o pai se culpa por ter aberto mais uma porta da corrupção, e se pergunta o que pensaria se um aluno o viesse pagar por ter tido uma boa aula.

O desenlace final da trajetória de pai e filho se dá pela compreensão do pai das habilidades de Felipe. Temos, nos últimos capítulos do livro, diversas referências às qualidades do menino. Natação, pintura, teatro, melhora na capacidade de abstração (várias delas relacionadas à apreciação do futebol), facilidade para usar a internet... De fato, os tempos são outros na família, o poder maravilhoso da rotina havia se instalado. A estabilidade no trabalho e as publicações de seus livros, associam-se a um novo momento da história do país, que, na visão do protagonista, parece ter mudado da água para o vinho, como se nenhum problema ainda atravancasse seu caminho. Ao lado das habilidades desenvolvidas por Felipe, procedimentos simples e cotidianos poderiam continuar sendo intransponíveis para ele, como ir à banca comprar jornal, por exemplo, o que seria uma verdadeira Odisseia. O pai vai revelando os gostos televisivos do filho e sua própria inclinação a acompanhar tudo que pode dos avanços da tecnologia para estimular o filho. Televisão, videocassete... Logo ele, que sempre foi tão avesso a isso, receando a transformação de milhões de habitantes numa massa inerte de robôs idiotas repetindo tudo que viam e ouviam. As reflexões sobre o império da imagem levam o pai a comentar as pinturas de Felipe. Colocaram-no na música (para a qual ele não manifestou interesse) e no teatro (chegando a encenar, de modo simplificado, a Comédia dos erros, de Shakespeare), mas foi na pintura que Felipe encontrou sua vocação. $\mathrm{O}$ menino faz até exposições com seus trabalhos em sua escola de pintura, seus quadros são vendidos, e ele mostra orgulhoso o dinheiro com que poderia comprar um carro, uma camisa do Atlético Paranaense (seu time) ou um álbum de 
figurinhas, o que para Felipe dá no mesmo. O menino se vê como um artista, no que o pai inveja o filho, pois sempre foi incapaz de afirmar-se como "escritor".

Alguns traços de amadurecimento de Felipe vieram se manifestando há certo tempo, orgulha-se da pequena barba que ele mesmo quer fazer, não assiste certos programas por serem para criança... Mas a sexualidade será um problema. Há episódios que deixaram o pai constrangido, em que Felipe, num primeiro caso, beijou a filha de um amigo na boca, dizendo tratar-se de sua namorada. Em casa, levou um sermão (ao qual Felipe responde com mais uma de suas teatralizações de si mesmo). Na próxima, ele se limitará a abraçar a menina, também dizendo tratar-se de sua namorada. O pai recorda-se de uma experiência amorosa sua também, na adolescência. Por indicação de seu guru, durante umas férias de verão, passou 40 dias numa ilha, na casa da argentina Dolores, e apaixonou-se pela filha dela, Virgínia, que, no entanto, nem o notava. Foi uma experiência de amadurecimento - bebeu, fumou, amou -, que o pai recorda ao observar o amadurecimento do próprio filho.

Mergulhamos todo tempo em suas reflexões, e suas frustrações e expectativas compõem nosso olhar sobre o romance. Por meio de flashbacks narrativos, sabemos que passou a infância em Santa Catarina e que perdeu o pai; conhecemos episódios de sua adolescência em Curitiba (o uso de alucinógenos e a prática de pequenos atos de vandalismo). Sua estada na Europa, vagos estudos em Coimbra (paralisados devido à Revolução dos Cravos), a imigração ilegal para a Alemanha e a passagem por Paris. Assim se compõe o passado desse pai que, ao final do romance, aparece estabilizado como professor universitário da área de linguística e escritor reconhecido.

O pai é um sujeito histórico. Diferentemente do filho, para quem, em função da síndrome, o tempo não existe, o pai se relaciona com o tempo de forma material, ele sabe dar uso a esse tempo, de modo que o romance também é um romance sobre a ascensão social de um escritor e professor universitário. Os indícios de seu despreparo são marcantes. Ao virar pai e ao se deparar com as dificuldades que surgem em função da doença do filho, é notória a necessidade que sente do guru.

Os sentimentos do pai em relação ao filho vão surgindo também em função dos progressos que esse tem na superação de suas dificuldades. O antigo rebelde é deixado de lado e até a polícia, antes inimiga, vira aliada. Tal fato passa também por aquilo que é narrado como no 
presente da narrativa: trabalha em casa/cuida do filho, corrige dissertações/cursa Letras, mora num sobradinho (entregue ao banco), vira professor em outra cidade, publica seu primeiro romance por uma grande editora e se torna professor universitário. Na mesma direção, o país muda e para o pai as novas contradições que surgem não interessam, tanto que param de ser incorporadas à narrativa ao final. Agora o foco é exclusivamente o bem-estar familiar. Nota-se a ascensão social de uma espécie de oposto do pobre-diabo (Paes, 1990), num movimento que também se dirige para o abandono das preocupações sociais, afinal, quando se atinge o berço esplêndido, o que está para além dele para de importar.

\section{Referências}

PAES, José Paulo. O pobre diabo no romance brasileiro. In: PAES, José Paulo. A aventura literária: ensaios sobre ficção e ficções. São Paulo: Companhia das Letras, 1990.

TEZZA, Cristóvão. O filho eterno. 9. ed. Rio de Janeiro: Record, 2010.

Recebido em 20 de junho de 2017.

Aprovado em 7 de janeiro de 2018.

\section{resumo/abstract/resumen}

\section{À procura do berço esplêndido: a trajetória de uma geração em $O$ filho eterno}

William Moreno Boenavides

O romance $O$ filho eterno, de Cristóvão Tezza, apresenta a trajetória de um pai não nomeado através do espelhamento em relação a seu filho, Felipe, portador da síndrome de Down. Nesse trabalho, procura-se enfatizar a trajetória do pai enquanto representante de uma geração que teve sua juventude marcada pela presença da ditadura militar e que vivenciou a transição para o processo chamado de "redemocratização" do Brasil. Para tanto, parte-se da hipótese de que o referido espelhamento se dá também em função da história do país, em relação ao qual o pai deixa entrever o viés de classe com o qual o relato é construído. Mostra-se que as maneiras pelas quais o romance vincula a trajetória 
do pai à do país variam ao longo do livro, mas se fazem presentes em recortes temporais enfatizados nas décadas de 1970, 1980 e nos anos 2000.

Palavras-chave: romance brasileiro contemporâneo, Cristóvão Tezza, classe social.

\section{Looking for the splendid crib: the trajectory of a generation in $O$ filho eterno}

William Moreno Boenavides

The novel $O$ filho eterno, by Cristóvão Tezza, presents the trajectory of an anonymous father through his relationship with his son, Felipe, who has Down syndrome. This essay proposes to read the father's story as a representative of a generation that experienced the impact of the military dictatorship and the country's redemocratization during their youth. The confluence between personal and national trajectories is related to the country's history and the father's class-based perspective of said history. The article examines the ways in which the novel links the trajectory of the father with that of the country and how it varies throughout the book, as indicated by specific temporal moments during the 1970s, 1980s and 2000s.

Keywords: contemporary Brazilian novels, Cristóvão Tezza, social class.

\section{En busca de la cuna espléndida: la trayectoria de una generación en $O$ filho eterno}

\section{William Moreno Boenavides}

La novela $O$ filho eterno, de Cristóvão Tezza, presenta la trayectoria de un padre no nombrado a través del reflejo en relación con su hijo, Felipe, portador del síndrome de Down. En este trabajo, se busca enfatizar la trayectoria del padre como representante de una generación que tuvo su juventud marcada por la presencia de la dictadura militar y que vivenció la transición al proceso llamado "redemocratización" de Brasil. Para ello, se parte de la hipótesis de que dicho reflejo se da también en función de la historia del país, con relación a la cual el padre deja entrever el sesgo de clase con el que se construye el relato. Se muestra que las maneras en que la novela vincula la trayectoria del padre a la del país varían a lo largo del libro, pero se hacen presentes en recortes temporales enfatizados en las décadas de los setenta, ochenta y en el año dos mil.

Palabras clave: novela brasileña contemporánea, Cristóvão Tezza, clase social. 